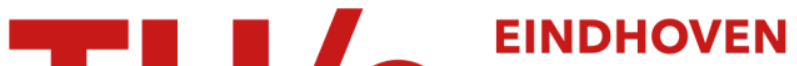 UNIVERSITY OF TECHNOLOGY
}

\section{The Strijp-S living-lab: testing innovative solutions for fault protection, self-healing, congestion management, and voltage control}

\author{
Citation for published version (APA): \\ Fonteijn, R., Roos, M., Nguyen, P., Morren, J., \& Slootweg, H. (2018). The Strijp-S living-lab: testing innovative \\ solutions for fault protection, self-healing, congestion management, and voltage control. In 201853 rd \\ International Universities Power Engineering Conference (UPEC) [8542117] Institute of Electrical and \\ Electronics Engineers. https://doi.org/10.1109/UPEC.2018.8542117
}

DOI:

10.1109/UPEC.2018.8542117

Document status and date:

Published: 01/01/2018

\section{Document Version:}

Accepted manuscript including changes made at the peer-review stage

\section{Please check the document version of this publication:}

- A submitted manuscript is the version of the article upon submission and before peer-review. There can be important differences between the submitted version and the official published version of record. People interested in the research are advised to contact the author for the final version of the publication, or visit the $\mathrm{DOI}$ to the publisher's website.

- The final author version and the galley proof are versions of the publication after peer review.

- The final published version features the final layout of the paper including the volume, issue and page numbers.

Link to publication

\footnotetext{
General rights

- You may freely distribute the URL identifying the publication in the public portal. follow below link for the End User Agreement:

www.tue.nl/taverne

\section{Take down policy}

If you believe that this document breaches copyright please contact us at:

openaccess@tue.nl

providing details and we will investigate your claim.
}

Copyright and moral rights for the publications made accessible in the public portal are retained by the authors and/or other copyright owners and it is a condition of accessing publications that users recognise and abide by the legal requirements associated with these rights.

- Users may download and print one copy of any publication from the public portal for the purpose of private study or research.

- You may not further distribute the material or use it for any profit-making activity or commercial gain

If the publication is distributed under the terms of Article $25 \mathrm{fa}$ of the Dutch Copyright Act, indicated by the "Taverne" license above, please 


\title{
The Strijp-S living-lab: testing innovative solutions for fault protection, self-healing, congestion management, and voltage control
}

\author{
R. Fonteijn*, M.H. Roos*, P.H. Nguyen*, J. Morren*†, J.G. Slootweg*† \\ *Electrical Energy Systems \\ Eindhoven University of Technology, \\ Eindhoven, the Netherlands \\ Email: r.fonteijn@tue.nl \\ ${ }^{\dagger}$ Asset Management, \\ Enexis Netbeheer, \\ 's Hertogenbosch, the Netherlands
}

\begin{abstract}
Distribution system operators are investigating methods to facilitate a high penetration of distributed energy resources while maintaining network reliability in a cost effective way. Some of the challenges associated with a high penetration of distributed energy resources are network overloading, voltage violations, and inadequate fault protection. Mitigation measures to these challenges are investigated in a newly developed livinglab in the district of Strijp-S, Eindhoven, the Netherlands. This living-lab is home to demonstrators from two $\mathrm{H} 2020$ projects: InterFlex and UNITED-GRID. The InterFlex demonstrator focuses on congestion management and voltage control through a dayahead and intraday flexibility market, while the UNITED-GRID demonstrator focuses on near real-time solutions for congestion management, voltage control, fault protection and self-healing. This paper addresses the innovative solutions which will be developed and tested in both demonstrators, in relation to the living-lab. Furthermore, an initial overview is given of a potential integrated approach to utilize both demonstrators in parallel.

Index Terms - congestion management, islanding, microgrids, power system protection, voltage control.
\end{abstract}

\section{INTRODUCTION}

Distribution networks are challenged by a growing number of distributed energy resources (DER). Among these challenges are network overloading, voltage violations, and inadequate fault protection systems. The reliability and security of the electricity system is impacted, and traditional solutions (e.g. network reinforcements) are often expensive to implement, or non-existent.

Distribution system operators (DSOs) are therefore investigating cost-effective alternatives to mitigate these challenges. In the city of Eindhoven, the Netherlands, the Strijp-S livinglab is home to demonstrators of two H2020 projects, in which measures to mitigate the DSO's challenges are researched.

This work has received funding from the European Union's Horizon 2020 research and innovation program under grant agreement $\mathrm{N}^{\circ} 731289$ and grant agreement $\mathrm{N}^{\circ} 773717$
The H2020 InterFlex project [1] focuses on congestion management and voltage control, and does so in an ahead-oftime manner. The H2020 UNITED-GRID project [2] proposes (near) real-time solutions for congestion management, voltage control, fault protection, and self-healing.

This paper addresses, on a conceptual level, the innovative solutions to be developed and tested in the context of the InterFlex and UNITED-GRID demonstrators in the Strijp-S living-lab. Section II elaborates on the Strijp-S living-lab. The InterFlex project in relation to the Strijp-S demonstrator is described in section III. Section IV elaborates on the Strijp$S$ demonstrator of the UNITED-GRID project. An initial overview of the relation and the possibilities for an integrated approach is provided in section V. An outlook into the expected results and future work is provided in section VI.

\section{STRIJP-S LIVING-LAB}

Strijp-S is a former industrial district in the Dutch city of Eindhoven, now housing small-medium enterprises and apartment buildings. The municipality of Eindhoven encourages the development of a living-lab in this district, resulting in various pilot projects within this area, and opportunities to add new projects in the future. This paper focuses on the InterFlex and UNITED-GRID project's activities in the living-lab, and the necessary equipment.

In the distribution network of the Strijp-S living-lab, measurement equipment is installed. Every medium voltage (MV) feeder, medium to low voltage (MV/LV) transformer and outgoing low voltage (LV) feeder are equipped with measurements equipment. 15-minute averaged rms values of current, voltage, and active and reactive power are automatically transmitted to a central database. The outgoing feeders of the MV/MV substation, and four MV/LV sub-stations are furthermore equipped with automation and remote switch-gear (distribution automation). Fig. 1 gives a simplified overview of the MV network, illustrating where the network's normaly 


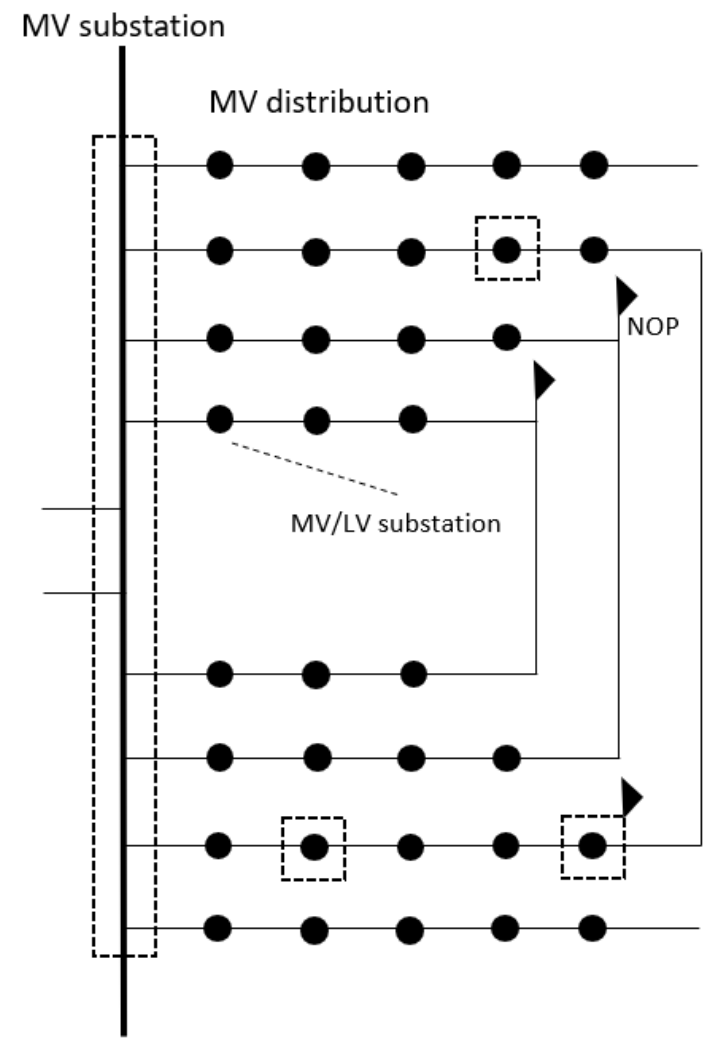

Fig. 1. Schematic overview of the MV network of Strijp-S. All MV feeders and MV/LV substations are equipped with measurement equipment. The dashed lines indicate the locations of distribution automation.

open points (NOPs) are situated, and distribution automation is installed. An example of the obtained measurement data can be found in Fig. 2.

In addition, synchronized measurement devices with a sampling rate of over $100 \mathrm{kHz}$ are added to the system, measuring phase currents and voltages. Ref. [3], [4] elaborate further on the measurement installation of the living-lab.

The flexibility is provided by a number of controllable distributed energy resources (DER). The DER are a $268 \mathrm{kWp}$ photovoltaic installation, a $255 \mathrm{kVA} / 315 \mathrm{kWh}$ battery energy storage system and 26 electric vehicle charge points of $22 \mathrm{~kW}$ each. These flexibility sources are clustered around two MV/LV substations. Three apartment buildings (approximately 350 apartments), and a parking garage provide the inflexible loads on these two substations.

\section{INTERFLEX ON STRIJP-S}

\section{A. Project goal}

The H2020 InterFlex project is a project in which twenty European partners collaborate on the topics distribution automation, energy storage, demand response, and large-scale integration of electric vehicles (EV). This is done in six demonstrators, spread over five countries (France, Germany, Czech, Sweden, and the Netherlands) [1]. The Dutch demonstrator is situated in the Strijp-S living-lab [5]. The goal

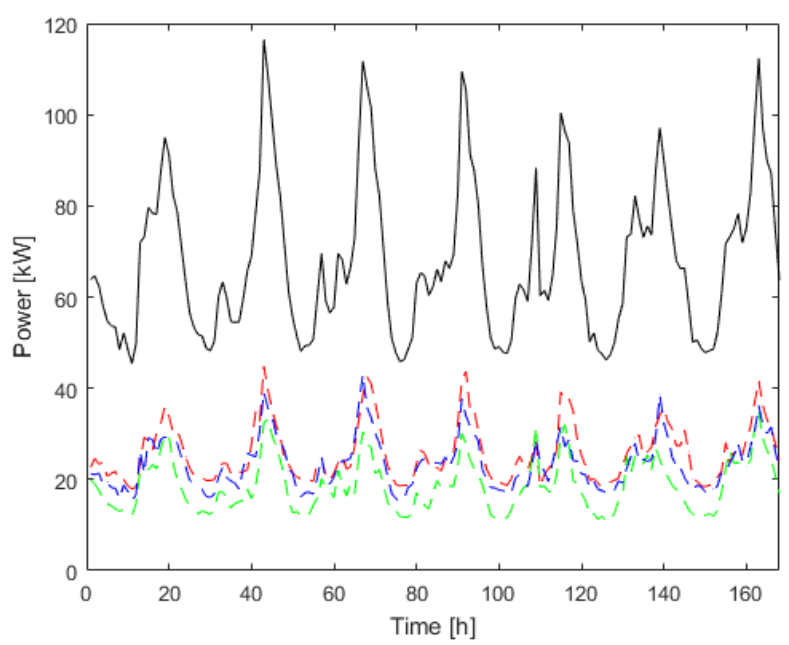

Fig. 2. Example of measurement profile on LV feeder. Active power $(\mathrm{kW})$ over time for the first week of January 2018. Phase 1 (red), phase 2 (green), phase 3 (blue), and sum of all phases (black).

of the Dutch demonstrator is to evaluate the application of large amounts of flexibility for the purpose of congestion management and voltage control. The necessary flexibility will be obtained from a local flexibility market [3]. The definition of flexibility by [6] is used. Flexibility is defined as "a power adjustment with a specific size and direction, sustained at a given moment for a given duration from a specific location within the network".

\section{B. Local flexibility market}

Flexibility for congestion management and voltage control will be traded on a local flexibility market, ahead-of-time, in program time units (PTUs) of fifteen minutes. Aggregators can offer their flexibility to the local flexibility market, both day-ahead and intraday, and the DSO can put out a request for this flexibility. However, aggregators are not obliged to offer their flexibility to the local flexibility market; Aggregators are able to trade with other interested parties and/or markets, making interested parties compete for the available flexibility. Examples of interested parties and other markets are the transmission system operator (TSO), balance responsible parties (BRPs), and/or wholesale markets.

Within the InterFlex Strijp-S demonstrator, a differentiation is made between commercial aggregators (responsible for flexibility trading on a market level), and local aggregators (responsible to ensure flexibility is locally available) [3]. The demonstrator uses multiple local and commercial aggregators to unlock the local flexibility.

The local flexibility market is based on the universal smart energy framework (USEF). USEF is a framework developed by an industrial consortium, which enables flexibility products to be formulated, and a flexibility market to run in parallel to the existing wholesale markets (e.g. day-ahead market, intraday market, imbalance market) [7]. 


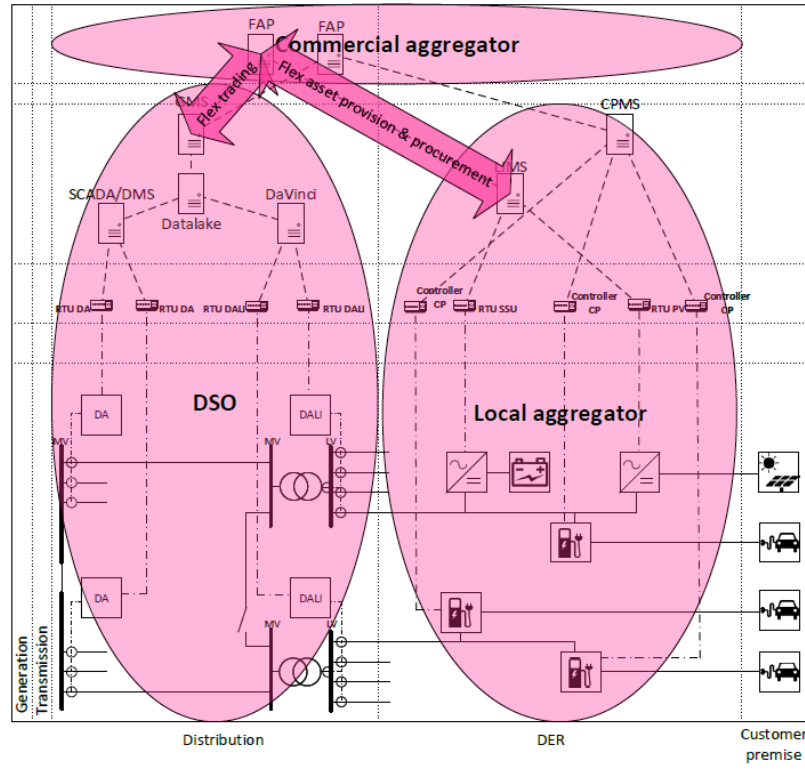

Fig. 3. InterFlex business level SGAM. Three roles (DSO, commercial aggregator, and local aggregator), and their interfaces.

Two modifications are made compared to the original USEF. According to the USEF specification, the DSO sends a flexibility request to an aggregator, who in turn sends a flexibility offer [8]. In this request, no distinction is made between the certainty with which a flexibility source is able to provide the promised flexibility. Furthermore, no restrictions on pricing are provided.

Within the Strijp-S local flexibility market, therefore two components are added to the flexibility request: the maximal price the DSO is willing to pay for flexibility and the minimal certainty a DSO needs, expressed as a sanction for noncompliance. As a result, iterations with the market can be limited, since all incoming offers comply with the boundaries set by the DSO. Furthermore, the DSO can select a flexibility offer based on both price and degree of needed certainty, rather than just price. Aggregators in return have the possibility to bid flexibility with a lower degree of certainty. It will be evaluated whether this opens the flexibility market for a broader set of flexibility sources.

\section{System architecture}

The smart grid architecture model (SGAM) [9] is used to visualize the high-level system architecture, and functions of the systems. The SGAM consists of five layers: the business layer, function layer, information layer, communication layer, and component layer. Since this paper focuses on the conceptual layer, we limit ourselves to the business layer (Fig. 3) and the function (Fig. 4) layer.

The business layer visualizes the roles in the system, and their respective interface with each other. The business interface between the local aggregator and commercial aggregator can be described as flex asset provision and procurement, while the interface between commercial aggregator and DSO

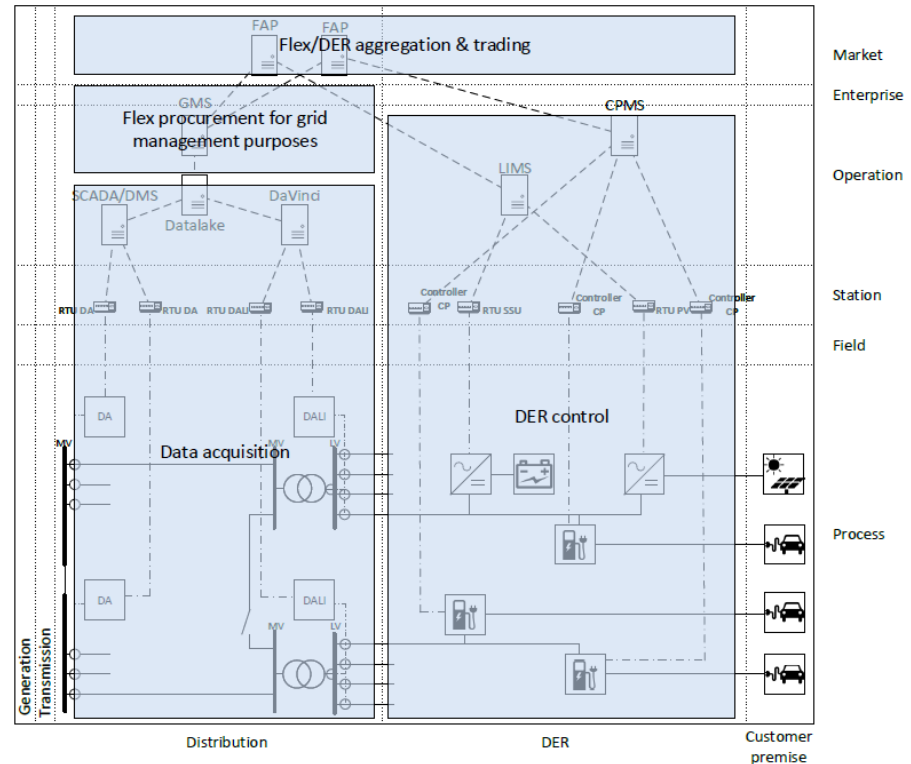

Fig. 4. InterFlex function level SGAM. Four function blocks can be distinguished.

can be described as flex trading. Since for the scope of the demonstrator the interface between commercial aggregator and wholesale markets is already implemented, this is not visualized in the SGAM.

The function layer describes the necessary functions the DSO and aggregators need in order to make this happen. The underlaying function of the local aggregator focuses on $D E R$ control. The function block of the commercial aggregator is described as flex/DER aggregation and trading. Conceptually a single commercial aggregator is able to procure flexibility from multiple local aggregators, while a single local aggregator is able to offer (parts of) its flexibility to multiple commercial aggregators. The DSO covers two function blocks, namely flex procurement for grid management purposes and data acquisition.

\section{Grid management system}

The DSO's function block flex procurement for grid management purposes is essential to obtaining flexibility from the market. The underlaying system (interfaces neglected) is the grid management system (GMS). The GMS is a system used by the DSO to determine the need for congestion management, and to formulate a request in the flexibility market. The GMS primarily consists of the following two modules: a load forecasting module to determine the load per transformer and LV feeder, and a decision-making module which translates the forecast into a need for flexibility and a corresponding flexibility request towards the market.

The load forecasting system uses historical measurements of voltage and power to provide a $48 \mathrm{~h}$ rolling forecast, both on a transformer level, and on a feeder level. This forecast system will have a 15-minutes resolution, in line with the market. Currently, a rough implementation of a multi-linear regression 


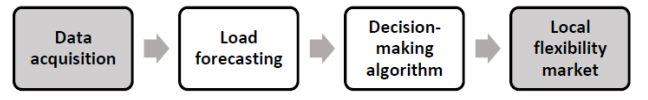

Fig. 5. InterFlex process steps to determine flexibility need by DSO, and request this need to the market.

based load forecasting model is available [10]. Alternative forecasting methods (e.g. auto regression, parametric, and machine learning models) will be evaluated. The goal is to determine the minimal necessary dataset, with which a satisfactory result can be obtained within a PTU.

The decision-making algorithm translates the load forecast to the need for flexibility. This then translates into a request for flexibility. As discussed in section III-B, for each flexibility request, the DSO needs to decide on the maximal price of flexibility, and the minimal sanction-price for non-compliance. Initially this decision will be made based on the forecasts, capacity ratings of feeders and transformers, and the nature of the problem (e.g. duration and percentage overloading). Then, additional parameters (to be determined) will be added, and the increased performance is evaluated with respect to additional complexity. The computation time has an upper limit corresponding with the time of a PTU.

The process steps of the GMS are illustrated in Fig. 5, where the interfaces towards other parts of the system (data acquisition and local flexibility market).

\section{E. Test case}

In the living-lab, the InterFlex demonstrator is used to test a day-ahead and intraday local flexibility market to prevent local network congestion. Part of the research is to analyze to what extent the DSO is able to procure flexibility in the market, when aggregators have the freedom to trade with other interested parties such as the TSO and BRPs.

In a later stage, this is expanded with voltage control. It will be evaluated to what extent flexibility from the market can be used for voltage control on primarily the outgoing feeders, and whether this can be done in parallel to marketbased congestion management.

\section{UNITED-GRID ON STRIJP-S}

\section{A. Project goal}

In the H2020 UNITED-GRID project, eleven partners collaborate to develop a toolbox. This toolbox can be directly integrated in existing distribution management systems via a cross-platform to achieve energy management, grid-level control and protection. During the project the toolbox is demonstrated in three demonstrators: in Sweden, France and the Netherlands. In the Netherlands, the Strijp-S living-lab will facilitate the demonstrator [4]. The effectiveness of the UNITED-GRID toolbox will be demonstrated by hosting more than $80 \%$ renewables at the demonstrators sites by utilizing novel real-time control, protection, and optimization methods [2]. The features to be demonstrated at the Strijp$S$ living-lab are: Real time network monitoring, advanced

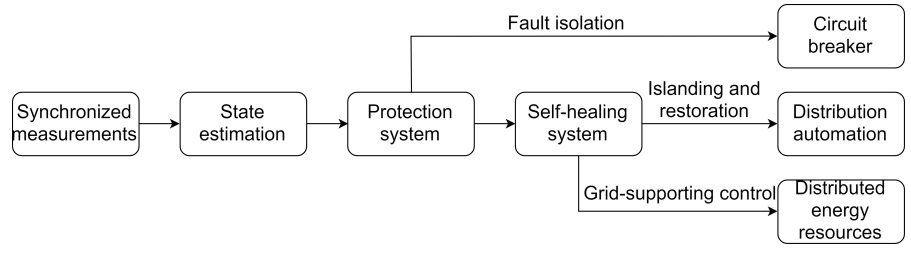

Fig. 6. UNITED-GRID fault protection and self-healing system.

protection schemes for active networks, automatic network reconfiguration and self-healing networks. The Strijp-S livinglab is exceptionally suited for these demonstrations due to the available smart measurement devices, and high penetration of network automation and DER.

The UNITED-GRID toolbox exists of the following systems which are researched during the project: congestion management, monitoring, control and protection, and ICT infrastructure. These systems are explained in sections IV-B, IV-C, and IV-D respectively.

\section{B. Congestion management}

For the research on congestion management, the UNITEDGRID project focuses on near real-time congestion management based on 15-minute intervals. Two strategies are investigated to resolve a congestion. Primarily, it is attempted to resolve a congestion through market-based congestion management. When this however fails, a direct-control strategy is applied.

A classification for network congestion will be implemented. The classification defines seven regimes of congestion, ranging from 'normal operation regime' (no congestion) to 'emergency regime' (network outage), with increasing steps of severity. During every 15-minute window, a forecast of the regime during the next 15-minute window is made. Based on the classification, it is evaluated what mitigation measure would be optimal.

UNITED-GRID further analyzes and compares existing market-based and direct-control congestion management which can be utilized for the regime. The results of the different methodologies are compared and recommendations on the optimal solutions are given.

\section{Monitoring, self-healing and protection}

Monitoring, self-healing and protection are three of the systems in the toolbox. The input for the monitoring system is generated by a combination of the $128 \mathrm{kHz}$ synchronized measurement devices and the 15-minute averaged measurement devices. The monitoring system utilizes the measurements for dynamic state-estimation (DSE) to make the distribution network observable [4].

When a fault occurs in the network the self-healing system applies the distribution automation to reconnect the unfaulted part of the distribution network, and to sectionalize the faulted part of the distribution network in individual islands. During islanded operation, the controllable DER within the islands are operated in grid-supporting mode to locally control voltage 


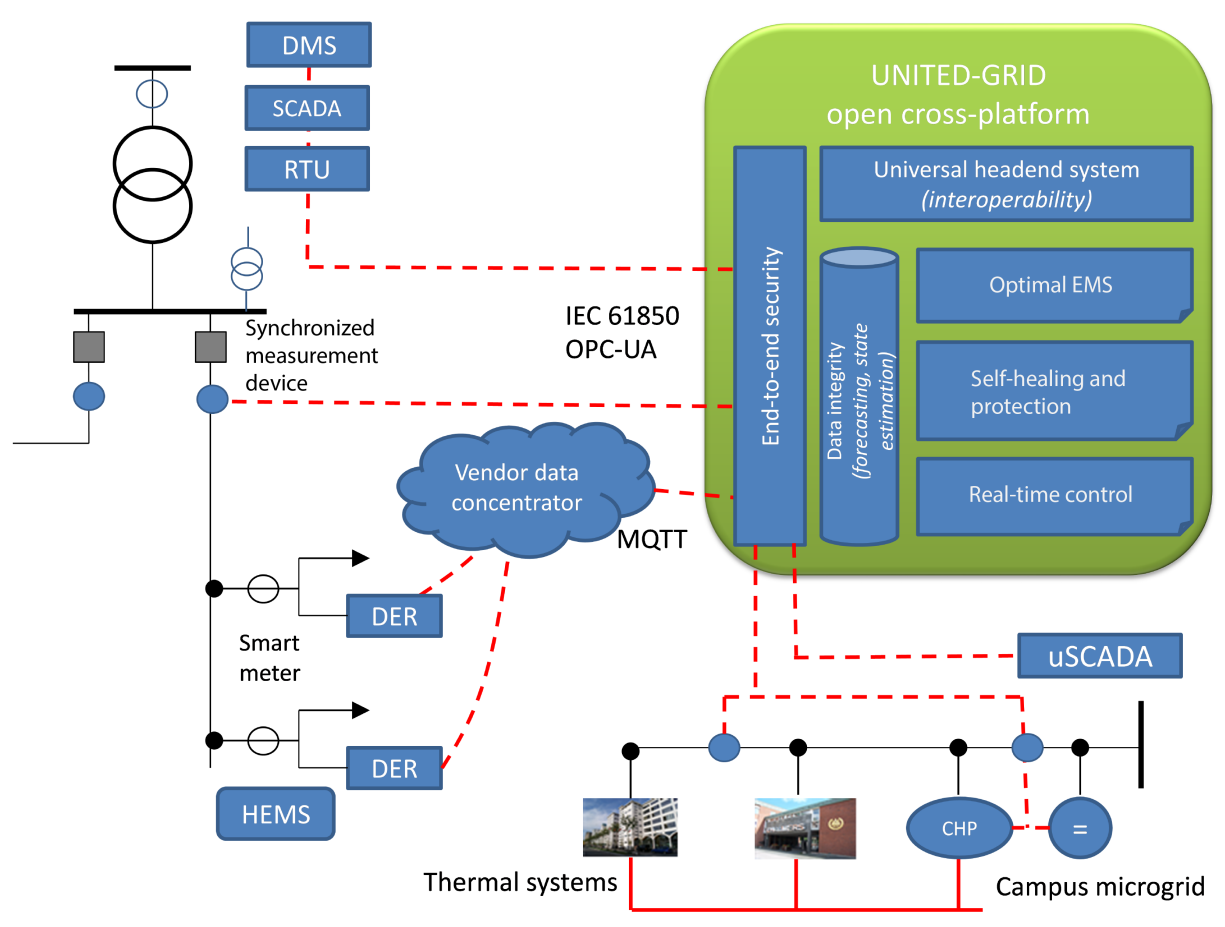

Fig. 7. UNITED-GRID overview of high-level system architecture, interfacing, and toolbox.

and frequency. After complete fault isolation, DSE is utilized to resynchronize and reconnect the island.

Conventional overcurrent protection is not suitable for the protection of active distribution networks. Therefore, a novel protection system e.g. DSE-based protection is utilized to offer fault protection to the network in both islanded and gridconnected operation. An overview of the monitoring, control and protection system is shown in Fig. 6.

\section{ICT infrastructure}

One of the investigated systems in the UNITED-GRID project is ICT infrastructure. The main goals of the research on this system are: specifying the requirements for real-time data measurements and the ICT infrastructure; assessing the interdependency between energy systems and the ICT infrastructure, and identify potential security issues; and assessing the required redundancy of the ICT infrastructure.

Since the ICT infrastructure and dependencies are of a facilitating nature, this paper will focus no further on this element.

\section{E. System architecture}

The high-level system architecture and interfaces of the UNITED-GRID project are shown in Fig. 7. The key element of this architecture is the UNITED-GRID toolbox, connecting to existing distribution management systems such as SCADA. To this end, six modules can be distinguished: End-to-end security, Data integrity, Universal headend system, Optimal EMS, Self-healing and protection, and Real-time control. The first three are facilitating, the latter three are related to the previous elements.
The module optimal energy management systems (EMSs) deals with market based congestion management. To this end, flexibility is unlocked both from the generation and the demand side. This system is described in Section IV-B.

The module self-healing and protection deals with fault protection and self-healing functionalities, using DSE and synchronized measurement equipment. This is explained in section IV-C.

The module real-time control deals with control of DER and automated switchgear to enable the congestion management and self-healing systems. The control of circuit breakers is performed directly by the protection system.

\section{F. Case studies}

In the living-lab, the UNITED-GRID toolbox is utilized for real-time network monitoring, advanced protection schemes for active networks, congestion management and self-healing networks. These applications enable the DSO to operate their network more effectively. The effectiveness of the toolbox on the living-lab is analyzed with two case studies.

The first case study is the adaptation of a local energy (flexibility) market, which involves consumer participation to create flexibility. In the second case study interaction between the DSO and charge point operators is enabled for local congestion management and voltage control. To assess the results of the case studies, three different aspects will be analyzed: network reliability, network losses and hosting capacity of DER.

\section{INTEGRATED APPROACH}

Initially, the InterFlex and UNITED-GRID demonstrators on Strijp-S are analyzed individually. However, the authors 
see opportunities for an integrated approach, in which a combination of the InterFlex and UNITED-GRID demonstrators can complement each other.

The InterFlex demonstrator on Strijp-S demonstrates the application of a local flexibility market for congestion management and voltage control, in a day-ahead and intraday setting. The gate-closure of the intraday market is several hours before the moment of delivery. After the gate closure, no further flexibility can be obtained. Furthermore, aggregators providing flexibility are not obliged to trade with the DSO. From a network perspective, this results in a risk of an unresolved congestion. The scope of the InterFlex demonstrator is now limited to ahead-of-time solutions, addressing unresolved congestion (near) real-time remains for future research or other projects.

The UNITED-GRID demonstrator on Strijp-S focuses on (near) real-time solutions. Congestions and voltage violations are resolved for the next PTU, while in case of a contingency or network fault, automated switch gear, and direct control of supply and demand result in an islanded network. The scope of the demonstrator however does not include ahead-of-time (i.e. day-ahead, intraday), where (mainly) congestion can already (partly) be resolved.

Combining the solutions proposed in the InterFlex and UNITED-GRID demonstrators, can fill the gap in the timeline and/or scope of the individual demonstrators. The various steps of both the InterFlex and UNITED-GRID demonstrators are combined in a timeline, visualised in Fig. 8.

The InterFlex demonstrator knows two moments of gateclosure, for the day-ahead market and intraday market. Flexibility is planned based on a 48 hours rolling forecast, and a decision to request flexibility. If the unavailability of flexibility in the ahead-of-time market remains, for example as a result of forecasting error or uncertainty, this should be solved in near real-time. The UNITED-GRID demonstrator operates in near real-time, with DSE and a 15 minutes rolling forecast of the severity of the problem. Based on UNITED-GRID, flexibility is obtained either by a market-based approach or through direct-control. The DSE enables the protection system to detect faults in the network. When a fault occurs, the selfhealing system utilizes direct control of DER and automated switchgear, and islanding abilities to heal the network and maximize the supplied load.

This paper only provides an initial overview of the possibilities of combining the work of both the InterFlex and UNITEDGRID demonstrators. Future research should address this in more detail.

\section{OUTLOOK}

Increasing amounts of DER are connected to distribution networks. To address the resulting challenges in the distribution network (e.g. congestion, voltage violations and inadequate fault protection), a living-lab is established in the district of Strijp-S, the Netherlands. This living-lab is home to two H2020 demonstrators, from the InterFlex project and UNITED-GRID project. This paper introduces the innovative

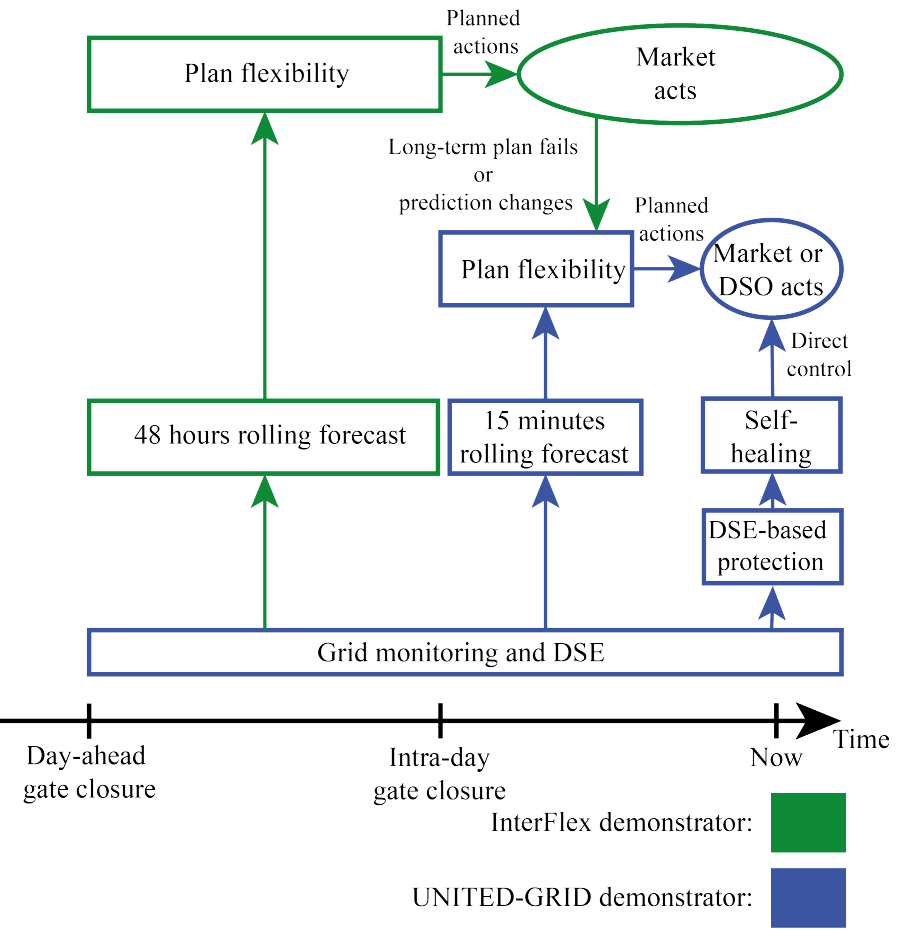

Fig. 8. Relation between InterFlex and UNITED-GRID projects on Strijp-S, as function of time.

solutions to be tested in these two demonstrators and proposes an integrated approach utilizing both demonstrators simultaneously.

The next steps are developing, validating, implementing and demonstrating the necessary systems, which will be done in the course of 2018-2019 for InterFlex, and 2018-2021 for UNITED-GRID. The results will be published in future papers.

\section{REFERENCES}

[1] "Interflex," 2018. [Online]. Available: http://interflex-h2020.com/

[2] "UnitedGrid," 2018. [Online]. Available: http://united-grid.eu/

[3] R. Fonteijn, D. Geelen, P. Klapwijk, J. Laarakkers, P. Rademakers, B. Ran, O. Westerlaken, and M. Willems, "Interflex Deliverable D7.1/D7.2: UC planning, District architecture requirements and tested innovations," Tech. Rep., 2017.

[4] M. Roos, R. Fonteijn, P. Nguyen, J. Morren, and J. Slootweg, "The Strijp-S living lab for embedded microgrid studies," in CIRED Workshop - Ljubljana 2018, unpublished.

[5] "InterFlex Strijp-S." [Online]. Available: https://www.interflexstrijp.nl/

[6] C. Eid, P. Codani, Y. Perez, J. Reneses, and R. Hakvoort, "Managing electric flexibility from Distributed Energy Resources: A review of incentives for market design," Renewable and Sustainable Energy Reviews, vol. 64, pp. 237-247, 2016.

[7] USEF Foundation, "USEF: The Framework Explained", Tech. Rep. February, 2015

[8] USEF Foundation, "USEF: The Framework specifications 2015," Tech. Rep., 2015.

[9] CEN/CENELEC/ETSI Joint Working Group on Standards for Smart Grids, "CEN-CENELEC-ETSI Smart Grid Coordination Group: Smart Grid Reference Architecture," Tech. Rep. November, 2012.

[10] P. Nijhuis, "Electricity demand forecasting at low voltage level for smart charging electric vehicles," MSc thesis, Eindhoven University of Technology, 2013. 